\title{
Accounting for electricity derivatives under IAS 39
}

\author{
Patrícia Teixeira Lopes \\ Faculty of Economics, University of Porto, Rua Dr Roberto Frias s/n, Porto 4200-464, \\ Portugal. \\ Tel: + 351225571100 (ext: 543), E-mail: patricia@fep.up.pt
}

Received (in revised form): 21st March, 2007

Patricia Lopes is Assistant Professor of Accounting at the Faculty of Economics of University of Porto. She obtained her PhD in Management Science from University of Porto. Her current research interests include international accounting, accounting harmonisation and IAS/IFRS. She has actively participated in various seminars and presented her research findings at major European and American Conferences. She has published in several international journals. In the past, she was Head of Training and Education at Euronext Lisbon and worked for the Research and Development Department of the Oporto Derivatives Exchange. She is a member of a European research project on the implementation of IFRS in Europe (Intacct project).

\section{Practical applications}

Electricity derivative users generally find IAS 39, the international standard for the recognition and measurement of financial instruments, to be a major challenge and have doubts about the impacts of the standard on Income statement amounts, namely in hedging strategies. IAS 39, as a general rule, requires that all derivatives are measured at fair value with movements in fair value recognised immediately through the Income Statement. IAS 39, however, also allows hedge accounting treatment for certain hedging relationships. Hedge accounting mitigates the volatile impact of derivative adoption in the Income Statement, by matching the timing of recognition of gains and losses on both the hedged item and the hedging instruments. Hedge accounting allows firms to override the normal accounting treatment of IAS 39. In order to apply hedge accounting rules, the transactions must meet the strict requirements defined in IAS 39. Yet, when hedges are accomplished with standard exchangetraded futures, compliance with IAS 39 hedge accounting rules is quite simple and straightforward. The use of electricity futures to hedge electricity price risk does not have major impacts in the Income Statement. Hedge accounting rules of IAS 39 mitigate volatility when there are balanced positions so that only real exposures give rise to income volatility.

\begin{abstract}
This paper analyses the impact of accounting rules on the accounting for hedges with energy derivatives in the context of the launch of MIBEL Derivatives Market.
\end{abstract}

contracts on commodities to be exempted from its rules. Those conditions are, however, quite strict and require a case-by-case analysis. IAS 39 requires all derivatives to be reported at fair value. Nevertheless, it allows for hedge accounting, provided that certain conditions are met, eliminating undesirable income volatility. Futures contracts pay-off profile is generally the inverse of the underlying item, and so futures tend to be easily 
qualified for hedge accounting rules of IAS 39, due to the way in which hedge effectiveness is measured. The paper shows that as far as energy producers and users are concerned, when hedges are accomplished with exchange-traded futures, compliance with IAS 39 hedge accounting rules is simple and straightforward. Journal of Derivatives \& Hedge Funds (2007) 13, 233-246. doi:10.1057/palgrave.jdhf.1850074

Keywords: electricity derivatives; hedge accounting; MIBEL

\section{INTRODUCTION}

The MIBEL Derivatives Market was launched on 3rd July, 2006 in a fundamental step in the Iberian Electricity Market ${ }^{1}$ building process. Since then, the different electricity market participants have at their disposal derivative to cover market risks, such as price variation. In MIBEL Derivatives Market are traded futures contracts. There are two basic types of MIBEL futures contracts: one has a physical delivery and the other foresees a purely financial settlement at maturity, with the peculiarity that both types of contracts benefit from a common order book. The remaining characteristics are common to both types of contracts: they are 'baseload' contracts; the contract unit is $1 \mathrm{MW} \times$ contract number of hours and the quotation and tick are in euros/MWh, with a 0.01 euros/MWh tick; delivery periods are weeks, months, quarters and years, and the spot reference price used for settlement at maturity for both types of contracts is the monetary value of the 'SPEL base' index, which represents an average price of electric energy in the Spanish zone, based on the values seen on the cash market managed by OMEL (the Iberian electricity spot market).
EU-listed firms are required to apply IFRS in their consolidated financial statements since $2005 .^{2}$ It is well documented that IAS 39, the international standard for the recognition and measurement of financial instruments, is the most complex standard in terms of understandability and, consequently, is the one that raises more difficulties in implementation by firms. ${ }^{3-6}$ Furthermore, it has generated a great deal of controversy among several agents of the accounting scene and it is far from being a closed issue. $^{7-11}$ This paper describes the key questions of accounting for derivatives raised by IAS 39, particularly regarding electricity futures. First, the conditions for exemption from IAS 39 are discussed. Then, the key questions of accounting for derivatives raised by IAS 39 are presented. This comprises the description of the IAS 39 general rule of including all derivatives in the Balance Sheet at fair value and of IAS 39 hedge accounting rules.

\section{ELECTRICITY DERIVATIVES UNDER IAS 39}

'IAS 39 Financial Instruments: Recognition and Measurement' deals with recognition, derecognition, measurement of financial instruments and hedge accounting. It applies to all firms and to all types of financial instruments. ${ }^{12}$ Financial instruments are defined as any contract that gives rise to both a financial asset of one firm and a financial liability or equity instruments of another firm. Moreover, financial assets are any assets that are cash, contractual rights to receive cash or another financial asset, contractual rights to exchange financial instruments under conditions potentially favourable or an equity instrument of another firm (eg stocks). Financial liabilities are 
contractual obligations to deliver cash or another financial asset or contractual obligation to exchange financial instruments under potentially unfavourable conditions.

A fundamental rethinking of all commodity contracts, in which electricity derivatives are included, is now required to determine whether they fall within the scope of IAS 39. This may require a thorough assessment of contracts on a case-by-case basis. The following analysis is specifically directed towards electricity futures.

Paragraph 5 of IAS 39 emphasises that IAS 39 applies to those 'contracts to buy or sell a nonfinancial item' if that contract can be net settled. Furthermore, the conditions under which a contract is considered as having net settlement are defined as follows:

(a) when the terms of the contract allow either party to settle it net in cash $^{13}$

Example: A sells to B, but B has the option of buying from the spot market and asking $A$ simply to pay B the cash difference between the original contract price and market

(a) when the above ability is not explicit in the terms of the contract, but the entity has a practice of settling similar contracts net;

Example: the firm has historically entered into sale contracts to offset pre-existing buy positions

(a) when, for similar contracts, the entity has a practice of taking delivery of the underlying and selling it within a short period after delivery for the purpose of generating a profit from short-term fluctuations in price; and

(b) when the nonfinancial item that is the subject of the contract is readily convertible to cash.

Therefore, there is an exemption from IAS 39: contracts that are entered into for the purpose of the receipt or delivery of a nonfinancial item in accordance with the firm's expected purchase, sale or usage requirements. These contracts are known as 'own use' contracts. Qualification for this exemption requires that three conditions are met:

(1) contracts are entered into and continue to meet the firm's own purchase, sale or usage criteria

(2) the contracts are designated for this purpose at inception and

(3) the contracts are settled by physical delivery.

This type of contract is accounted for as an executory contract, that is, it has an off-balance sheet treatment until completed. Nevertheless, there is a presumption in IAS 39 that a contract to which the above (b) or (c) applies is never entered into for the purpose of the receipt or delivery of the nonfinancial item and, accordingly, is always within the scope of IAS 39. This is known as the similarity criterion. Contracts to which (a) or (d) apply must be evaluated to determine whether they are entered into for the purpose of the receipt or delivery of the nonfinancial item in accordance with the firm's expected purchase, sale or usage requirements and, accordingly, whether they are within the scope of IAS 39. Thus, whether or not the contract falls within the scope of IAS 39 is determined by business practices, control objectives and management's intent about physical delivery, in addition to proving dissimilarity with other contracts that fall within (b) or (c) above. If the physical delivery on the contract is not certain to occur from the inception, the contract falls within the scope of IAS 39. Note that electricity is a commodity 
actively quoted in both spot and futures markets, meaning that electricity always meets the 'readily convertible to cash' criterion.

The underlying premise behind this IASB's position is that most commodity contracts involve interchangeable (standardised) units that place the firm in the same economic position if the contract physically delivers or if the contract settles for cash. When a firm uses contracts to manage supply on an economic basis (ie securing prices rather than volumes), those contracts should be considered financial instruments and treated under the scope of IAS 39.

In addition, an analysis of the definition of derivative in IAS 39 is useful. IAS 39 defines derivative as a contract:

(a) whose value changes in response to an underlying variable (ie a specified interest rate, security price, commodity price, foreign exchange rate, index of prices or rates, a credit rating or credit index or other variable)

(b) that requires little or no initial net investment and

(c) that is settled at a future date.

All these three criteria are met by electricity futures negotiated at MIBEL Derivatives Market (Table 1). All contracts are settled at a future date and, as initial investment, only require a margin (which represents an initial net investment much smaller than would be required for other types of contracts that have a similar response to changes in market factors), which, according to IAS 39, is not considered an initial investment (IAS 39 Implementation Guidance, para. B.10). Besides, as an underlying may be any variable, including commodities, electricity futures clearly meet the definition of derivative and meet the intention of
IASB regarding the scope of IAS 39 (IAS 39

Basis for conclusions, para. 221).

Concluding, 'own use' exception is included in IAS 39 and, it is generally accepted. As far as exchange-traded derivatives are concerned, the adoption of 'own use' exception must be evaluated on a case-by-case basis. Nevertheless, it can be said that the derivatives accounting rules of IAS 39 will have implications for firms involved with electricity futures.

\section{MARK TO MARKET ACCOUNTING}

IAS 39 requires all derivatives, including futures contracts, to be carried at fair value. The gains or losses on the contract should be recognised in the Income Statement as they occur.

Since all derivatives must be measured at fair value, it is very important to understand what fair value is and how the fair value of electricity futures traded at OMIP is measured.

Fair value is defined in IAS 39 as the amount for which an asset could be exchanged, or a liability settled, between knowledgeable, willing parties in an arm's length transaction. IAS 39 sets out clearly that the best evidence of fair value is quoted prices in an active market. Thus, when they exist they are used to measure the financial asset or financial liability.

Measuring fair value of exchange-traded derivatives and, specifically, the fair value of futures contracts traded at OMIP, is a simple process. For initial recognition, fair value of futures contracts traded at market rates is nil. For subsequent measurement, once these products have daily cash settlement based on the settlement price that is available each day from OMIP, fair valuing is performed automatically. The settlement price is used to calculate the profit and losses of the position in futures. ${ }^{14}$ 
Table 1: Futures contracts traded at Mibel Derivatives Market

MIBEL base load financial futures contracts

Underlying: The notional supply of electricity at a constant power of $1 \mathrm{MW}$ during all the hours of the delivery period. The delivery is purely financial based on the Spot Reference Price.

The MIBEL Base Load Financial Futures contracts benefit from a common order book with the MIBEL Base Load Physical Futures.

Settlement: Daily cash settlement of the price differences between the Spot Reference Price and the LTD futures settlement price, applicable to the number of hours of each and every day of the delivery period.

\section{MIBEL base load physical futures contracts}

Underlying: The supply of electricity at a constant power of $1 \mathrm{MW}$ during all the hours of the delivery period. The delivery will be physical on OMEL's Mercado Diario (Day-Ahead Market).

The MIBEL Base Load Physical Futures contracts benefit from a common order book with the MIBEL Base Load Financial Futures.

Settlement: Includes two components:

(a) Positions are sent for physical delivery on OMEL's Mercado Diario.

(b) Cash settlement of the price differences between the Spot Reference Price and the LTD futures settlement price, applicable to the number of hours of each and every day of the delivery period.

Other characteristics (common to both futures)

'Baseload' contracts

Contract unit: $1 \mathrm{MW} \times$ contract number of hours

Quotation and tick: in ./MWh, with a 0.01 ./MWh tick

Delivery periods: weeks, months, quarters and years

Daily Cash Settlement (mark-to-market)

Settlement Price (during the trading period): The last traded price if it is within the closing bid-ask spread; If the last traded price is not situated in the closing bid-ask spread, the bid or ask price that is closest to the last traded price; If there is no traded price, the average of the closing bid-ask prices; If there is no traded price, and no closing spread bid-ask, the last settlement price is adopted; Nevertheless, OMIP ${ }^{\mathrm{a}}$ can always use quotes from the Price Committee $^{\star}$ if it considers that the prices are not market representative;

Spot reference price used for settlement at maturity: monetary value of the 'SPEL base' index, which represents an average price of electric energy in the Spanish zone, based on the values seen on the cash market managed by OMIE. ${ }^{b}$

Source: MIBEL website, 13th June, 2006

${ }^{a}$ OMIP is the managing entity responsible for the management of the MIBEL derivatives market, jointly with OMIClear - (Energy Markets Clearing Company) Sociedade de Compensação de Mercados de Energia S.A., a company constituted and totally owned by OMIP, which executes the role of Clearing House and Central Counterparty of operations carried out on the market.

${ }^{b}$ OMIE is the managing entity responsible for the management of the MIBEL spot electricity market.

${ }^{\star}$ The Price Committee is made up voluntarily by Trading Members. 


\section{HEDGE ACCOUNTING}

As stated above, the basic principle in IAS 39 is that all derivatives are carried at fair value with gains and losses in the Income Statement. Derivatives are, however, commonly used to hedge recognised assets and liabilities that are measured at cost, amortised cost or at fair value with gains and losses in equity, as well as items such as forecasted transactions or firm commitments that are not recognised in the balance sheet. This creates a mismatch in the timing of gain and loss recognition, creating accounting volatility in the Income Statement that does not reflect economic volatility. Hedge accounting seeks to overcome this problem by matching the timing of recognition of gains and losses on both the hedged item and the hedging instruments.

Hedge accounting can be defined as a method of reflecting a commercially hedged position in the accounts, so that the revaluation of the derivative does not pass through Income Statement until the transaction concerned occurs. Thus, hedge accounting can mitigate volatility when there are balanced positions - so that only real exposures give rise to income volatility.

Hedge accounting allows firms to override the normal accounting treatment of IAS 39, but for IASB, it is a privilege and, as such, it must be earned. To apply hedge accounting rules, the transactions must meet the strict requirements defined in IAS 39, which are often considered complex and onerous. We show that when hedges are accomplished with standardised exchange-traded futures, such as the case of OMIP electricity futures, compliance with IAS 39 hedge accounting rules is quite simple and straightforward.

\section{Hedged items and hedging instruments}

Hedge accounting requires the item being hedged and the hedging instrument to be identified and designated as such since the inception of the hedge.

The hedged item can be a recognised asset or liability, an unrecognised firm commitment or a highly probable forecast transaction. Some common examples of qualifying hedged items related to electricity price risk are, for example, highly probable forecast sales of electricity and highly probable forecast purchases of electricity.

The aggregation of similar assets or similar liabilities to constitute the hedged item is possible under IAS 39, provided that:

(1) the individual assets or individual liabilities in the group share the risk exposure that is designated as being hedged and

(2) the change in fair value attributable to the hedged risk for each individual item in the group shall be expected to be approximately proportional to the overall change in fair value attributable to the hedged risk of the group of items.

The hedging of an overall net position does not qualify for hedge accounting. Approximately the same effect, however, can be achieved by designating part of one of the gross position, equal in amount to the net position (eg, if an entity has a firm commitment to make a purchase in a foreign currency of $\mathrm{CU}^{15} 100$ and a firm commitment to make a sale in the foreign currency of CU90, it can hedge the net amount of CU10 by acquiring a derivative and designating it as a hedging instrument associated with CU10 of the firm purchase commitment of CU100). 
IAS 39 previews that for a financial asset or financial liability, a portion of the risk or cashflows can be designated as a hedged item (eg, only the EURIBOR portion of a debt instrument and not the credit spread). This ability to designate a portion, however, does not extend to hedges of nonfinancial assets and liabilities. These may be hedged only in their entirety for all risks or for foreign exchange risk, because of the difficulty of isolating and measuring the appropriate portion of the cash flows or fair value changes attributable to specific risks other than foreign currency risks (IAS 39 Application Guide, para. 100).

Regarding hedging instruments, IAS 39 states that all derivatives may be designated as hedging instruments. ${ }^{16}$ Futures traded at OMIP are thus eligible for entering hedging relationships and can be treated under hedge accounting rules.

Additionally, among several requirements of IAS 39 regarding hedging items, two are relevant within hedging with electricity derivatives. A derivative may be designated as a hedging instrument in its entirety or as a proportion (ie a percentage of the notional amount). A hedging relationship, however, may not be designated for only a portion of the time period during which a hedging instrument remains outstanding.

\section{Accounting for hedges}

According to IAS 39, hedge accounting may be applied to three types of hedging relationships:

(1) fair value hedge

(2) cash flow hedge and

(3) hedge of a net investment in a foreign operation (as defined in IAS 21).

The first two are directly relevant to hedging of commodity price risk and, thus, their qualifying conditions and accounting rules are described below. Note, however, that cash flow hedge will be the most relevant type of hedging for the energy firms, in the form of hedging of future production and sales or future acquisitions and consuming.

\section{Fair value hedge}

When the objective is to cover the risk of changes in the fair value of:

(a) a recognised asset or liability or

(b) an unrecognised firm commitment or

(c) an identified portion of such an asset, liability or firm commitment

that is attributable to a particular risk and could affect profit or loss; this hedge is a fair value hedge under IAS 39 terminology.

A fair value hedge shall be accounted for as follows:

(a) the gain or loss from remeasuring the hedging instrument (in the case, an electricity future) at fair value shall be recognised in the Income Statement and

(b) the gain or loss on the hedged item attributable to the hedged risk shall be adjusted in the amount of the hedged item and be recognised in the Income Statement. This applies even if the hedged item was measured at cost.

Regarding fair value hedge, a special look towards the hedge of a firm commitment is needed. IAS 39 defines firm commitment as a binding agreement for the exchange of a specified quantity of resources at a specified price on a specified future date or dates. An example 
of a hedge of a firm commitment could be the hedge of the change in electricity price relating to an unrecognised contractual commitment by a utility firm to purchase electricity at a fixed price. This hedge operation is a hedge of an exposure to a change in fair value, according to IAS 39, and as such, it should be accounted for as a fair value hedge.

Fair value hedge accounting rules apply to unrecognised firm commitments, that is, an off balance sheet item whose fair value changes would not be otherwise recognised in the Income Statement. Thus, IAS 39 states that when the hedged item is a firm commitment, the subsequent cumulative change in the fair value of the firm commitment attributable to the hedged risk is recognised as an asset or liability with a corresponding gain or loss recognised in the Income Statement.

Then, the initial amount of the asset or liability that results from the enterprise meeting the firm commitment is adjusted to include the cumulative change in the fair value of the firm commitment attributable to the hedged risk that was recognised in the Balance Sheet.

\section{Cash flow hedge}

When the objective is to hedge the exposure to variability in cash flows that is attributable to:

(a) a particular risk associated with a recognised asset or liability (such as all or some future interest payments on variable rate debt) or

(b) a highly probable forecast transaction

that could affect the Income Statement, this hedge is a cash flow hedge according to IAS 39 terminology.

Future cash flows referred to in (a) relate, in most of the cases, to variable rate debt and therefore are not relevant to commodities. Future cash flows referred to in (b) regarding forecast sales or purchases are related to risks in commodities' prices.

IAS 39 defines forecast transaction as an uncommitted but anticipated future transaction. An example of a cash flow hedge with electricity futures is the case of a firm that sells electricity and mitigates a potential fall in the price of electricity by taking short positions on the futures market. Another case may be that of an electricity consumer who buys a future contract to hedge against the risk of electricity price rising in a determined future electricity price spike period.

A cash flow hedge should be accounted for as follows:

(a) provided the hedge is effective (see below), the gain or loss on the hedging instrument (electricity future) shall be recognised directly in equity and

(b) the ineffective portion of the gain or loss on the hedging instrument shall be recognised in profit or loss.

IAS 39 allows that, until the expected transaction takes place, the effective part of the hedge is not recognised in the Income Statement. This procedure mitigates the volatility that could be induced in the Income Statement if this special treatment were not allowed. In fact, once a forecast transaction is not taken to the Balance Sheet, the general rule of considering all gains and losses of derivatives in the Income Statement would generate income volatility, because there would not be the offsetting accounting entry of the hedged position.

Regarding the moment in which those gains and losses recognised in equity are transferred to 
the Income Statement, the IAS 39 general rule is only when the hedged transaction affects profit or loss (eg, when the forecast sell occurs).

If a hedged forecast transaction results in the recognition of a nonfinancial asset or liability, however, firms have a choice. They can either:

(a) adjust the amount of the asset or liability by the hedging gain or loss previously deferred in equity - basis adjustment or

(b) leave the hedging gain or loss in equity and transfer it to the Income Statement when the hedged asset or liability affects profit or loss.

In the approach stated in (a), the hedging gain and loss is automatically recycled to the Income Statement when the hedged asset or liability is sold. ${ }^{17}$ The choice should be applied consistently to all similar hedges.

Table 2 summarises the accounting treatments for derivatives allowed by IAS 39, highlighting the Balance Sheet and Income Statement impacts of each one.

\section{Criteria for obtaining hedge accounting}

Hedge accounting is an exception to the usual accounting principles for financial instruments. IAS 39 therefore requires hedge relationships to meet certain criteria in order to qualify for hedge accounting. The specific conditions are:

(a) the hedging relationship and the entity's risk management objective and strategy for undertaking the hedge must be formally designated and documented (Table 3) from

Table 2: Balance sheet and income statement impacts of fair value hedges, cash flow hedges and no hedge accounting

\begin{tabular}{lll} 
Type of operation & Balance sheet impact & Income statement impact \\
\hline Fair value hedge & $\begin{array}{l}\text { Both derivative and hedged } \\
\text { item are reported at fair value }\end{array}$ & $\begin{array}{l}\text { Changes in fair value of the derivative are } \\
\text { reported in Income Statement; Offsetting } \\
\text { changes in fair value of hedged item are } \\
\text { also reported in Income Statement. }\end{array}$
\end{tabular}

Cash flow hedge Derivative is reported at fair value; Changes in fair value of derivative are reported in equity

No hedge accounting
Derivative is reported at fair value
No immediate Income Statement impact. Changes in fair value of derivative are either adjusted in the amount of the asset or liability when they enter the Balance Sheet or transferred into Income Statement when the expected transaction affects income.

Changes in fair value are reported in Income Statement. There are no offsetting changes in the fair value of the hedged item. 
Table 3: Hedge documentation template

(1) Description of risk management objective and strategy

(2) Type of hedging relationship (fair value hedge, or cash flow hedge)

(3) Nature of the risk being hedged (commodity)

(4) Identification of the hedged item

a. Is the hedged item a forecast transaction? If yes:

b. Expected hedged amount

c. Nature of forecast transaction

d. Expected timing of the forecast transaction

e. Expected price for forecast transaction

f. Why it is highly probable to occur

g. Method of reclassifying into profit and loss amounts deferred in equity (basis adjustment or not)

(5) Identification of hedging instrument

(6) Prospective effectiveness testing

a. Description of the method and its application to testing

b. Frequency of testing

(7) Retrospective effectiveness testing

a. Description of the method and its application to testing

b. Frequency of testing

the inception of the hedge. ${ }^{18}$ IAS 39

requires that hedge documentation includes

the identification of the hedging

instrument, the hedged item or transaction, the nature of the risk being hedged and how the entity will assess the hedging instrument's effectiveness

(b) the hedge must be expected to be highly effective in achieving offsetting changes in fair value or cash flows attributable to the hedged risk and this effectiveness can be reliably measured

(c) the effectiveness of the hedge must be assessed regularly throughout its life (see below).

In the case of a hedge of a forecast transaction, this transaction must be 'highly probable'. IAS
39 gives additional guidance on what is meant by 'highly probable'. Basically, it means a much greater likelihood of happening than the term 'more likely than not'. IAS 39 states that an assessment of the likelihood that a forecast transaction will take place must not be based solely on management's intentions and it should be supported by observable facts. ${ }^{19}$

\section{Other issues relevant for hedge accounting}

\section{Hedge effectiveness}

IAS 39 requires two kinds of effectiveness tests:

(a) A prospective effectiveness test - this is a forward-looking test. At the inception of 
the hedge and in subsequent periods, the hedge is expected to be highly effective in future periods.

(b) A retrospective effectiveness test - this is a backward-looking test. At the time the firm prepares its interim or annual financial statements, a test of whether a hedging relationship has actually been highly effective in a past period.

A hedge is regarded as highly effective only if both the following conditions are met:

(a) The hedge passes the prospective test. That is, at the inception of the hedge and in subsequent periods, the hedge is expected to be highly effective.

This expectation can be demonstrated in various ways: a comparison of past changes in the fair value or cash flows of the hedged item that are attributable to the hedged risk with past changes in the fair value or cash flows of the hedging instrument, or by demonstrating a high statistical correlation between the fair value or cash flows of the hedged item and those of the hedging instrument.

In this test, IAS 39 does not require a hedge ratio one to one. In order to improve hedge effectiveness, the amount of the hedging instrument may be greater or less than that of the hedged position

(b) The actual results of the hedge are within a range of 80-125 per cent.

Example: If actual results are such that the loss on the hedging instrument is CU120 and the gain on the cash instrument is CU100, offset can be measured by 120 / 100 , which is 120 per cent, or by $100 / 120$, which is 83 per cent. In this example, assuming the hedge meets the condition in (a), the entity would conclude that the hedge has been highly effective.

IAS 39 does not specify a single method for assessing hedge effectiveness prospectively and retrospectively. The IASB accepts that the method an entity adopts depends on its risk management strategy. The documentation of the hedging strategy must include the procedures for assessing effectiveness. The most common methods used are:

(1) Critical terms comparison: This method consists of comparing the critical terms (eg, notional or principal amounts, term, pricing, timing and currency) of the hedging instrument with those of the hedged item. If all the principal terms match exactly, the hedge is expected to be highly effective.

(2) Ratio analysis: This method consists of comparing the change in fair value of the hedging instrument with the change in fair value of the hedged item. This test can be performed either (1) on a cumulative basis (with the comparison performed from the inception of the hedge) or (2) on a periodby-period basis (with comparison performed from the last testing date). Here, the criterion of 80-125 per cent mentioned above applies.

(3) Regression analysis: This method consists of measuring the strength of the statistical relationship between the hedged item and the hedging instrument. Regression analysis is a means of expressing how one variable (the dependent) varies with changes in another variable (the independent). In the context of hedging effectiveness, the dependent variable 
reflects the change in the value of the hedging instrument and the independent variable the change in the value of the hedged item. Then, critical tests determine the effectiveness of the hedge: (1) slope line must be negative and between -0.8 and -1.25; (2) $R^{2}>0.96$; and (3) F-statistic significant at 95 per cent or greater confidence level.

The requirement to reassess and report hedge effectiveness is sometimes seen as a very complex and costly task. Hedge effectiveness with exchange-traded futures, namely with OMIP electricity futures, however, is simple to achieve and to measure. Indeed, if the underlying terms of the hedging instrument and of the hedged asset, firm commitment or highly probable forecast transaction are the same, the changes in fair value and cash flows attributable to the risk being hedged may be likely to offset each other fully. This is the case of hedging electricity spot positions based on the SPEL index with OMIP futures. If the future contract is for the same quantity of electricity and for the same time period as the hedged position, the hedge with the future contract is assumed to be highly effective. In this case, the critical terms comparison method is used for the prospective effectiveness test and it is not necessary to carry out a quantitative test. Regarding the retrospective test, from an accounting point of view, the ratio analysis has the advantage of using the accounting entries of the gains and losses in the derivative positions.

\section{Discontinuing hedges}

Hedge accounting must be discontinued prospectively when any of the following occur:

(a) a hedge fails an effectiveness test (b) the hedged item is sold or settled

(c) the hedging instrument is sold, terminated or exercised

(d) management decides to revoke the designation or

(e) for a hedge of a forecast transaction, the forecast transaction is no longer highly probable.

All future fair value changes in a derivative hedging instrument are recognised in the Income Statement. Similarly, changes in the fair value of the hedged item that arise after the hedging is discontinued are accounted for as they would be without hedge accounting.

Additionally, IAS 39 prescribes how any existing hedge accounting gains or losses already recorded in previous periods should be addressed. The objective is to avoid hedge accounting being claimed in one period and then to cherry pick an alternative accounting result in another period. When a forecast transaction is no longer highly probable, but still expected to occur, hedging gains and losses recognised in equity remain in equity until the transaction affects profit or loss. When a forecast transaction is no longer expected to occur, the cumulative gain or loss on the hedging instrument recognised in equity shall be recycled immediately to the Income Statement.

\section{Presentation}

IASs are not prescriptive about where gains and losses from derivatives should be shown in the Income Statement. 'IAS 1 Presentation of financial statements' describes the minimum line items to be included on the face of the Income Statement. Additional line items may be presented to comply 
with specific standards. In general, firms should apply the following:

- Gains and losses from hedging instruments are presented in the same line item as the gains and losses from the hedged items. Regarding the Cash Flow Statement, cash flows arising from hedging instruments are classified as operating, investing or financing activities, on the basis of the classification of the cash flows arising from the hedged item.

- Gains and losses from derivatives not included in hedging relationships are not presented as part of the entity's revenue, cost of sales or operating expenses. They should be presented either in a separate line item in the Income Statement or within 'other operating income and expense'.

\section{Disclosures}

Requirements for disclosing information in financial statements about financial instruments are in IFRS 7 Financial Instruments: Disclosures, which requires specific disclosures for hedge accounting in its paragraphs 22-24. Disclosures for hedge accounting include:

- a description of each type of hedge

- a description of the hedging instruments, and their fair values at the reporting date

- the nature of the risks being hedged (commodities)

- regarding cash-flow hedges:

- the periods when the cash flows are expected to occur and when they are expected to affect profit or loss

- the amount recognised in equity

- the amount removed from equity and included in profit or loss

- the amount removed from equity and included in the initial cost or other carrying amount of a nonfinancial asset or liabilityin fair value hedges:

- gains or losses on the hedging and on the hedged item.

\section{CONCLUDING REMARKS}

IAS 39 represents a major challenge in accounting practices for financial instruments, in general, and for derivatives, in particular. It is admittedly a complex standard and has attracted attention both from academia and practitioners. This paper aims at describing the accounting rules for electricity futures. The main conclusions may be stated as follows:

(1) Under certain conditions, IAS 39 allows contracts on commodities to be exempted from its rules; those are known as 'own use' contracts.

(2) Those conditions are, however, quite strict and require a case-by-case analysis.

(3) Although IAS 39 requires all derivatives to be reported at fair value, it allows for hedge accounting, provided that certain conditions are met.

(4) Futures contracts pay-off profile is generally the inverse of the underlying item, and so futures tend to be easily qualified for hedge accounting rules of IAS 39, due to the way in which hedge effectiveness is measured.

(5) As far as energy producers and users are concerned, when hedges are accomplished with exchange-traded futures, compliance with IAS 39 hedge accounting rules is simple and straightforward.

\section{Legislation}

Regulation no. 1606/2002, European Commission IAS1 Presentation of Financial Statements, IASB 
IAS 32 Financial Instruments: Presentation, IASB

IAS 39 Financial Instruments: Recognition and Measurement, IASB

IFRS 7 Financial Instruments: Disclosures, IASB

FAS 133 Accounting for Derivative Instruments and Hedging Activities, FASB.

\section{References and Notes}

1 The Iberian Electricity Market (Mercado Ibérico de Electricidade - MIBEL), constitutes a joint initiative from the Governments of Portugal and Spain, and it is a step in the development of an internal electricity market.

2 Regulation no.1606/2002, the so-called 'Regulation on IAS', states that for each financial year starting from the 1st January, 2005, European Union firms whose securities are traded on a regulated market shall prepare their consolidated accounts in accordance with the standards of IASB (International Accounting Standards — IAS and International Financial Reporting Standards - IFRS) adopted by the Commission.

3 BDO, Deloitte, Ernst\&Young, G. Thornton, KPMG and PricewaterhouseCoopers (2003) 'GAAP Convergence 2002: A Survey of National Efforts to Promote and Achieve Convergence with International Financial Reporting Standards'.

4 Jermakowicz, E. (2004) 'Effects of Adoption of International Financial Reporting Standards in Belgium: The Evidence from BEL-20 Companies', Accounting in Europe, Vol. 1(September), pp. 51-70.

5 Sucher, P. and Jindrichovska, I. (2004) 'Implementing IFRS: A Case Study of the Czech Republic', Accounting in Europe, Vol. 1(September), pp. 109-141.

6 Larson, R. and Street, D. (2004) 'Convergence with IFRS in an Expanding Europe: Progress and Obstacles Identified by Large Accounting Firms' Survey', Journal of International Accounting, Auditing \& Taxation, Vol. 13, No. 2, pp. 89-119.

7 Pacter, P. (2005) 'What Exactly is Convergence', International Journal of Accounting, Auditing and Performance Evaluation, Vol. 2, No. 1/2, pp. 67-83.

8 Whittington, G. (2005) 'The Adoption of International Accounting Standards in the European Union', European Accounting Review, Vol. 14, No. 1, pp. 127-153.

9 Walton, P. (2004) 'IAS 39: Where Different Accounting Models Collide', Accounting in Europe, Vol. 1, pp. 5-16.

10 Gélard, G. (2004) 'What can be Expected from Accounting Standards', Accounting in Europe, Vol. 1(September), pp. 17-20.
11 Hague, I. (2004) 'IAS 39: Underlying Principles', Accounting in Europe, Vol. 1(September), pp. 21-26.

12 With a few exceptions only, such as interest in subsidiaries, associates and joint ventures, leases, employee benefit plans and insurance contracts.

13 Or in another financial instrument or by exchanging financial instruments.

14 IAS 39 gives additional guidance on the appropriate quoted market price. For an asset held or liability to be issued, it is usually the current bid price, and for an asset to be acquired or liability held, it is the asking price. When current bid and asking prices are unavailable, the price of the most recent transaction provides evidence of the current fair value. If conditions have changed since the time of the transaction, the fair value reflects the change in conditions by reference to current prices or rates for similar financial instruments. The fair value of a portfolio of financial instruments is the product of the number of units of the instrument and its quoted market price. Note that IAS 39 uses the term 'asking price' referring to the 'current offer price' in the context of quoted market prices, and the term 'the bid-ask spread' to include only transaction costs.

15 Currency units.

16 Provided they are entered with an external party and except for most written options.

17 Or depreciated or impaired.

18 IAS 39 permits an entity to designate and formally document a derivative contract as a hedging instrument after entering into the derivative contract, only prospectively. That is, a hedge relationship cannot be designated retrospectively.

19 'In assessing the likelihood that a transaction will occur, an entity should consider the following circumstances: (a) the frequency of similar past transactions; (b) the financial and operational ability of the entity to carry out the transaction; (c) substantial commitments of resources to a particular activity (eg, a manufacturing facility that can be used in the short run only to process a particular type of commodity); (d) the extent of loss or disruption of operations that could result if the transaction does not occur; (e) the likelihood that transactions with substantially different characteristics might be used to achieve the same business purpose (for example, an entity that intends to raise cash may have several ways of doing so, ranging from a short-term bank loan to an offering of ordinary shares); and (f) the entity's business plan.' IAS 39 Implementation Guidance (para. F.3.7). 